\title{
Recovery of Gold and Silver and Removal of Copper, Zinc and Lead Ions in Pregnant and Barren Cyanide Solutions
}

\author{
Gabriela Figueroa ${ }^{*}$, Jesus L. Valenzuela1 ${ }^{1}$, Jose R. Parga², Victor Vazquez ${ }^{1}$, \\ Alejandro Valenzuela ${ }^{1}$ \\ ${ }^{1}$ Department of Chemical Engineering and Metallurgy, University of Sonora, Hermosillo, Mexico \\ ${ }^{2}$ Department of Materials Science, Technological Institute of Saltillo, Saltillo, Mexico \\ Email: "gabyvfm@hotmail.com
}

Received 18 January 2015; accepted 9 February 2015; published 12 February 2015

Copyright (C) 2015 by authors and Scientific Research Publishing Inc.

This work is licensed under the Creative Commons Attribution International License (CC BY). http://creativecommons.org/licenses/by/4.0/

(c) (7) Open Access

\section{Abstract}

Over the past decade the concern about toxic metals in freshwater has increased. Environmental laws such as the Clean Water Act have forced industries that produce metal containing wastewater to treat their wastewater prior to discharge. The purpose of this study was to investigate the use of a novel method for the minimization of heavy metals in the wastewater from the mining industry. A very promising electrochemical treatment technique that does not require chemical additions is electrocoagulation (EC) and sulphide precipitation. The present study has been done for the recovery of gold and silver contained in pregnant solution from the cyanidation process using the electrocoagulation technology with iron electrodes; that is a developed alternative technology for the Merril-Crowe process. The average gold and silver content in pregnant solution was 4.27 and $283 \mathrm{ppm}$ respectively and the recoveries were $92 \%$ for gold and $95 \%$ for silver, with optimum operating parameters of $\mathrm{pH} 10$, residence time of 20 minutes and addition of sodium chloride of 4 gr/L. The results of precipitation process show that the elimination of lead, zinc, cooper and iron ions from the barren solution was successful, with optimum operating parameters of $\mathrm{pH} 3$ and residence time of 15 minutes, and the recoveries were $99 \%$ of these ions. Finally the characterization of the solid products of gold and silver formed during the EC process with Scanning Electronic Microscope was performed. Results suggest that magnetite particles and amorphous iron oxyhydroxides (lepidocrocite) were present.

\section{Keywords}

Electrochemical Process, Precipitation Process, Gold and Silver Cyanides

\footnotetext{
${ }^{*}$ Corresponding author.
}

How to cite this paper: Figueroa, G., Valenzuela, J.L., Parga, J.R., Vazquez, V. and Valenzuela, A. (2015) Recovery of Gold and Silver and Removal of Copper, Zinc and Lead lons in Pregnant and Barren Cyanide Solutions. Materials Sciences and Applications, 6, 171-182. http://dx.doi.org/10.4236/msa.2015.62020 


\section{Introduction}

Gold and silver are the most popular precious metals for investors. Early studies on the dissolution of gold in cyanide solution in the presence of sulfide minerals have shown that heavy metal components, such as $\mathrm{Cu}, \mathrm{Pb}$, Fe and Zn cyanide ions, significantly increase the consumption of both cyanide and oxygen [1] [2]. In addition, the sulfide component has been shown to have a strong impact on the gold leaching kinetics [3]-[5]. The leaching behavior of gold in the presence of sulfide minerals depended strongly on both the solubility of the sulfides and the oxygen concentration in the solution [5]. Based on the experiments observation, it is postulated that sulfide ions (formed by the decomposition of sulfide minerals) show detrimental effect on the cyanidation kinetics of gold and silver.

Cyanidation has been used for over 100 years to extract precious metals from sulfide ores. Despite this fact, the reactions involved are not fully understood. More gold is recovered by cyanidation than by any other process. In cyanidation, metallic gold is oxidized and dissolved in an alkaline cyanide solution [6]. The oxidant employed is atmospheric oxygen, which, in the presence of an aqueous solution of sodium cyanide, causes the dissolution of gold and the formation of gold cyanide and sodium hydroxide, according to the so-called Elsner reaction (Equations (1) and (2)) [7]:

$$
\begin{aligned}
& 4 \mathrm{Au}+8 \mathrm{NaCN}+2 \mathrm{H}_{2} \mathrm{O}+\mathrm{O}_{2} \rightarrow 4 \mathrm{NaAu}(\mathrm{CN})_{2}+4 \mathrm{NaOH} \\
& 4 \mathrm{Ag}+8 \mathrm{NaCN}+2 \mathrm{H}_{2} \mathrm{O}+\mathrm{O}_{2} \rightarrow 4 \mathrm{NaAg}(\mathrm{CN})_{2}+4 \mathrm{NaOH}
\end{aligned}
$$

The cyanide concentration determines the rate of anodic gold dissolution while the oxygen reduction rate is dependent on the concentration of dissolved oxygen. In the cyanidation process, free cyanide ions in solution can be provided only at $\mathrm{pH}>9.3$. The $\mathrm{pH}$ of the pulp can be increased with the additions of alkali hydroxides $\left(\mathrm{NaOH}, \mathrm{KOH}, \mathrm{Ca}(\mathrm{OH})_{2}\right.$, etc.), known as proactive alkalis. Also, details of this electrochemical reaction have received considerable attention, and under certain circumstances, the reaction is limited by the coupled diffusion of $\mathrm{CN}^{-}$and $\mathrm{O}_{2}$ to the gold surface. Therefore, the initial rate of gold dissolution is largely controlled by the factors such as cyanide and oxygen concentrate, $\mathrm{pH}$, solid-liquid interface, Eh of the slurry, alkalies, particle size and temperature [8].

In the metallurgical operation plants, the concentration of cyanide used to dissolve gold in ores is typically higher than the stoichiometric ratio, since other minerals get dissolved by cyanide. Free cyanide produces complexes with several metallic species, especially transition metals of copper, zinc and iron, which show a broad variation in both stability and solubility, as discussed by Rehman [9].

$$
\mathrm{M}^{+x}+\mathrm{CN}_{y}^{-} \rightarrow \mathrm{M}(\mathrm{CN})_{y}^{x-y}
$$

Most common copper minerals are soluble in the dilute cyanide solution, typically found in leach conditions during the gold cyanidation process. Minerals such as azurite and malachite are fast leached and are soluble in dilute cyanide solutions [10]. The next process for recovery gold and silver from the pregnant cyanide solutions is the Merrill Crowe and the increasingly stringent limitations on the purity of the Dore for the refining process have created a growing interest on the development of a novel process for the removal of precious metals from the pregnant cyanide solution before cementation in the filter press [6].

In general, the quality of precipitate in the cyanidation process will depend upon the nature of the ore being treated. The richer the pregnant solution is, the better the quality of the precipitate of gold and silver is, although this is modified by the presence of metals, such as copper, lead, zinc and iron. This behavior can be explained from Table 1 of the electromotive force of the metals [11].

In Table 1, each member displaces each succeeding member from salt solution; that is, metallic zinc replaces copper, silver and gold; copper replaces silver; lead replaces gold; platinum replaces gold, and so forth. However it should be noted that these reactions are not reversible and that the metals above hydrogen are soluble in acids while the metals below hydrogen are insoluble in acids. Therefore, cementation is a process in which a

Table 1. Electromotive series of the metals.

\begin{tabular}{ccc}
\hline Metal/V & Metal/V & $\mathrm{Metal} / \mathrm{V}$ \\
$\mathrm{Zn}-0.8$ & & $\mathrm{Cu}-0.34$ \\
$\mathrm{Fe}-0.44$ & $\mathrm{H}_{2}-0.0$ & $\mathrm{Ag}-0.8$ \\
$\mathrm{~Pb}-0.13$ & & $\mathrm{Au}-1.68$ \\
\hline
\end{tabular}


metal ion in solution is precipitated onto more electronegative metal surfaces.

Commonly the metals found in the precipitate are: gold, silver, copper, arsenic, lead and iron. This may be due to precipitation of base metals. Silica is found due to improved clarification, and it is in colloidal form. Lime is found mainly due to very high protective alkalinity [12]. Therefore, an acid treatment of precipitates is needed in order to remove undissolved copper, zinc and iron. Treatments with sulfuric or hydrochloric acids are the most common. When sulfuric acid is used, it is used as a $10 \%-20 \%$ solution in water. The acid is added gradually to the precipitate and the whole mixture is kept well stirred in a steel tank. Due to the formation of gases, an appropriate fume hood must be used. The precipitate or sludge is washed with warm acid water after acid leaching treatment for removing the soluble copper-zinc sulfates and other salts. The precipitate of gold and silver with remaining lead is then dried and prepared for melting. Lead in the precipitate lowers the quality of the Dore [13]. Therefore, the purpose of this study was to investigate the use of a very promising electrochemical treatment technique that does not require chemical additions like electrocoagulation (EC) with iron electrodes for the recovery of gold and silver from the pregnant solution and for the minimization of heavy metals in the barren solution from the filter press because of using the sulphide precipitation process.

\section{Electrocoagulation Process for Precious Metals Recovery}

The EC process operates on the principle that the coagulation is caused by electrolytically produced ions from iron and aluminum anodes, which corrode during electrolysis and cause the release of contaminants from an aqueous medium. The idea in flowing EC techniques is to take advantage of the combined effects of electrolysis gases $\left(\mathrm{H}_{2}\right.$ and $\left.\mathrm{O}_{2}\right)$ and the production of polyvalent cations from the oxidation of corrodible anodes such as (Fe and $\mathrm{Al}$ ). These consumable or sacrificial metal electrodes are used to continuously produce the metal ions in the vicinity of the anode.

The EC process can be considered as an accelerated, corrosion process was green rust (GR) is an intermediate product that is responsible for the removal of contaminants (suspended and dissolved solids, metals, organic compounds, etc.). EC mechanisms may involve oxidation, reduction, decomposition, deposition, coagulation, absorption, adsorption, precipitation and flotation. EC operates on the principle that hydrolized cations produced electrolytically from iron and/or aluminum anodes enhance the coagulation of contaminants from an aqueous medium.

In the EC technique, the production of polyvalent cations from the oxidation of the sacrificial anodes ( $\mathrm{Al}$ or $\mathrm{Fe})$ and the production of electrolysis gases $\left(\mathrm{O}_{2}\right.$ and/or $\left.\mathrm{H}_{2}\right)$ are directly proportional to the amount of current applied (Faraday's law). The electrolysis gases enhance the froth flotation of the coagulant material [14]-[16]. A schematic representation of the EC process is shown in Figure 1. As mentioned above, the gas bubbles produced by the electrolysis carry the pollutant to the top of the solution where it is concentrated, collected and removed. The removal mechanisms in EC may involve oxidation, reduction, decomposition, deposition, coagulation, absorption, adsorption, precipitation and flotation.

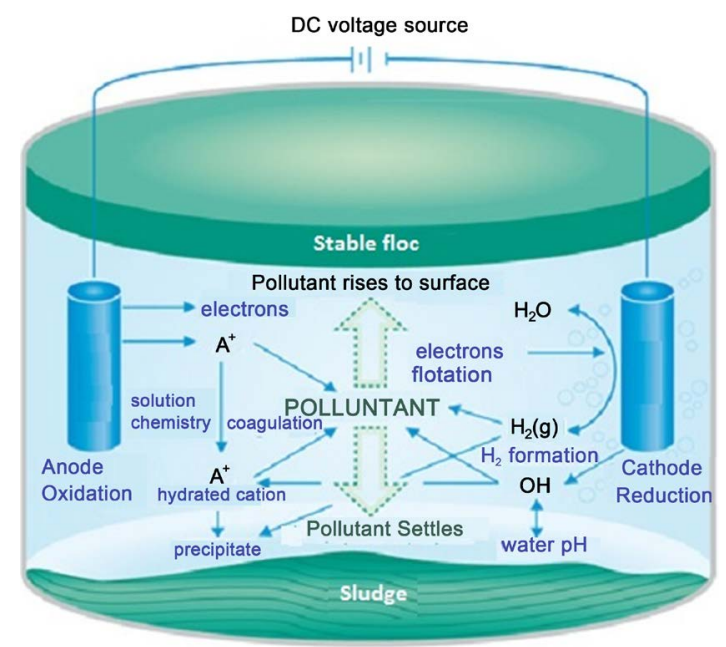

Figure 1. Schematic diagram of the electrocoagulation process. 


\section{Theoretical Analysis by Using First Order Rate Equation}

In mostly cases of recovery precious metals, the cementation electrochemical reactions follow first-order reaction kinetics and generally are limited by diffusion of the noble metal ion through the mass-transfer boundary layer. In some cases the structure and morphology of the reaction product can have a significant effect on passivating the surface in other cases.

Most of the cementation reactions are found to be first-order diffusion processes [17] with respect to the noble metal ion, and the reaction velocity constant, $k$, for such a reaction may be computed from the general firstorder rate Equation (4):

$$
\frac{\mathrm{d} c}{\mathrm{~d} t}=\frac{-k A C}{V}
$$

If $k$ is not concentration dependent and the area is unhanging Equation (5) may be integrated resulting in the integrated first-order expression,

$$
\log \frac{C}{C o}=-\frac{k A t}{2.3 V}
$$

$k$ is the reaction velocity constant $(\mathrm{cm} / \mathrm{sec}) ; A$ is reaction surface area $\left(\mathrm{cm}^{2}\right)$; and $V$ is the solution volume rate $\left(\mathrm{cm}^{3}\right)$. In Equation (4), it can be seen that the cementation rate is a function of the reaction area $A$. It has been shown by many investigators that in almost all cementation systems the initial exposed geometric area of the precipitant metal can be used in the analysis of initial rate data.

However, in a more general sense, the area term is not always that simple to evaluate due to the changing nature of the noble metal deposit which grows on the active metal during the course of the reaction.

Experimental investigations [17] indicate that most cementation reactions are controlled by a mass transfer process, film diffusion, as indicated by the results presented in Table 2 .

Accord with the Table 2, we are going to use the first order rate expression Equation 5 to analysis the electrocoagulation results.

\section{Chemical Precipitation for Cyanides Copper, Zinc and Iron Ions}

After the precipitation is the creation of a solid in a solution or inside another solid during a chemical reaction or by diffusion in a solid. When the reaction occurs in a liquid solution, the solid formed is called the "precipitate". The chemical that causes the solid to form is called the "precipitant". Without sufficient force of gravity (settling) to bring the solid particles together, the precipitate remains in suspension.

Chemical precipitation is effective and by far the most widely used in industrial process, because it is relatively simple and inexpensive to operate. In precipitation process, chemical react with heavy metal ions to form insoluble precipitants [18].

Table 2. Data for selected cementation aqueous systems at $25^{\circ} \mathrm{C}$ [17].

\begin{tabular}{cccc}
\hline System & $\Delta \boldsymbol{E}_{\boldsymbol{o}}, \boldsymbol{V}$ & Activation energy, Kcal/mole & Reaction velocity constant, cm/sec \\
\hline $\mathrm{Ag}^{+} / \mathrm{Cu}$ & 0.46 & $2.0-5.0$ & $2.5-6.0 \times 10^{-2}$ \\
$\mathrm{Ag}^{+} / \mathrm{Cu}\left(\mathrm{CN}^{-}\right)$ & 1.83 & $3.7-5.8$ & $1.5 \times 10^{-2}$ \\
$\mathrm{Ag}^{+} / \mathrm{Fe}\left(\mathrm{Cl}^{-}\right)$ & 1.29 & 3.0 & $2.2 \times 10^{-2}$ \\
$\mathrm{Ag}^{+} / \mathrm{Zn}\left(\mathrm{CN}^{-}\right)$ & 0.95 & 5.5 & $5.5 \times 10^{-2}$ \\
$\mathrm{Ag}^{+} / \mathrm{Zn}$ & 1.56 & $2.0-6.0$ & $2.6-2.1 \times 10^{-2}$ \\
$\mathrm{Cu}^{2+} / \mathrm{Zn}$ & 1.10 & 3.1 & $1.6-2.1 \times 10^{-2}$ \\
$\mathrm{~Pb}^{2+} / \mathrm{Fe}$ & 0.31 & 12.0 & - \\
$\mathrm{Pb}^{2+} / \mathrm{Zn}$ & 0.64 & - & $0.64 \times 10^{-2}$ \\
$\mathrm{~Pb}^{2+} / \mathrm{Cu}$ & 0.49 & $9.5-7.4$ & $0.36-2.3 \times 10^{-2}$ \\
\hline
\end{tabular}




\section{Sulphide Solubility Curves}

The thermodynamic equilibrium involved in metal sulphide precipitation has been proposed as [19]:

$$
\begin{gathered}
\mathrm{H}_{2} \mathrm{~S} \Leftrightarrow \mathrm{HS}^{-}+\mathrm{H}^{+} \mathrm{K}_{\mathrm{p} 1}=\frac{\left[\mathrm{HS}^{-}\right]\left[\mathrm{H}^{+}\right]}{\left[\mathrm{H}_{2} \mathrm{~S}\right]} \mathrm{pK}_{1}=6.99 \\
\mathrm{HS}^{-} \stackrel{\mathrm{Kp} 2}{\Leftrightarrow} \mathrm{S}^{2-}+\mathrm{H}^{+} \mathrm{K}_{\mathrm{p} 2}=\frac{\left[\mathrm{S}^{2-}\right]\left[\mathrm{H}^{+}\right]}{\left[\mathrm{HS}^{-}\right]} \mathrm{pK}_{2}=17.4 \\
\mathrm{M}^{2+}+\mathrm{S}^{2-} \Leftrightarrow \mathrm{MS}(\mathrm{s}) \\
\mathrm{M}^{2+}+\mathrm{HS}^{-} \Leftrightarrow \mathrm{MS}(\mathrm{s})+\mathrm{H}^{-}
\end{gathered}
$$

The concentration of sulphur species is a strong function of $\mathrm{pH}$, as shown in Figure 2.

Accord with Figure 2, the arguments for its preferential use of sulphide precipitation are based on the high degree of metal removal at relatively low $\mathrm{pH}$ values; the sparingly soluble nature of sulphide precipitates; favorable dewatering characteristics and stability of the metal sulphides formed. However when choosing a metal sulphide precipitation route, various complexities are encountered. The first issue is the nature of the particles formed in metal sulphide precipitation. Because of the extremely low solubilities of most metal sulphide salts, the supersaturation created by the interaction of the aqueous sulphide and metal species can be very high (up to $10^{35}$ and higher). Thus, the dominant precipitation mechanisms are homogeneous nucleation and limited crystal growth. Attrition of the sulphide crystals due to turbulence, combined with possible aggregation of the solid particles. These can cause problems in downstream processing and should be avoided. The second issue is the formation of aqueous polysulphide complexes under conditions of excess sulphide which can be experienced either globally or locally [20].

Table 3 shows the constants sulphides solubility of some compounds.

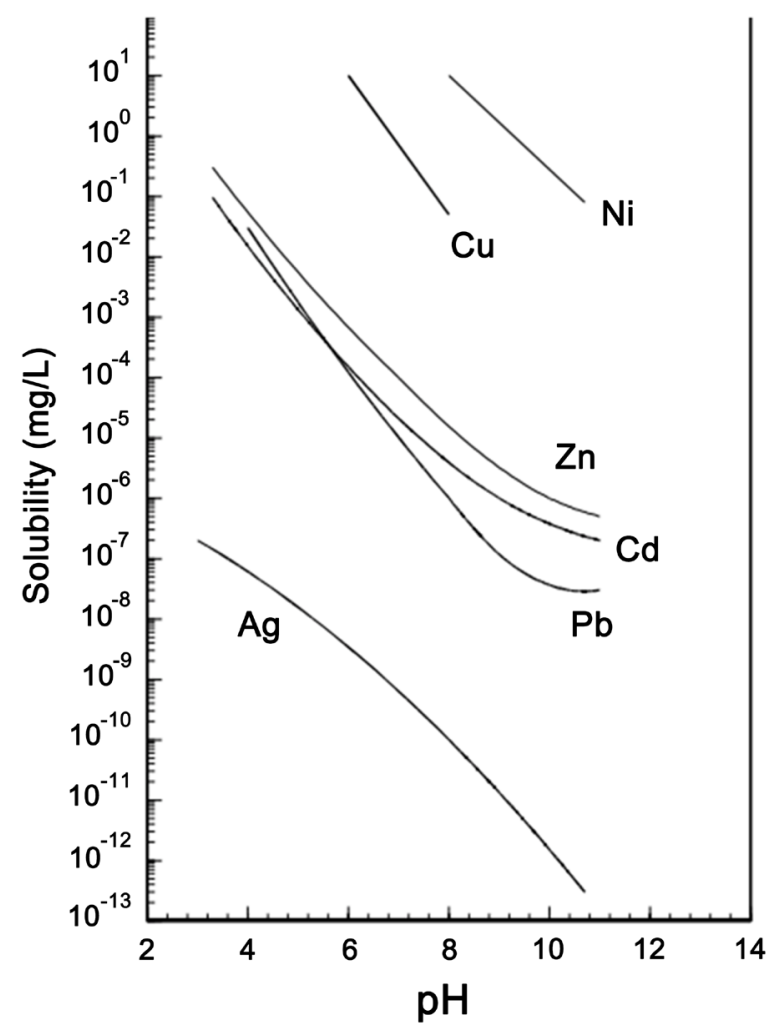

Figure 2. Sulphide solubility curves. 
Table 3. Constants sulphides solubility.

\begin{tabular}{ccc}
\hline Compound & $\mathrm{K}_{\mathrm{sp}}$ & Concentration of ions (g Ion/l) in saturated solution \\
$\mathrm{CuS}$ & $8 \times 10^{-37}$ & $9.2 \times 10^{-23}$ \\
$\mathrm{Ag}_{2} \mathrm{~S}$ & $8 \times 10^{-51}$ & $5.44 \times 10^{-17}$ \\
$\mathrm{PbS}$ & $3 \times 10^{-28}$ & $1.84 \times 10^{-14}$ \\
$\mathrm{CdS}$ & $1 \times 10^{-27}$ & $6 \times 10^{-15}$ \\
$\mathrm{NiS}$ & $4 \times 10^{-20}$ & $1.18 \times 10^{-12}$ \\
$\mathrm{ZnS}$ & $2 \times 10^{-23}$ & $3.46 \times 10^{-12}$ \\
$\mathrm{Cd}(\mathrm{OH})_{2}$ & $1.8 \times 10^{-15}$ & - \\
$\mathrm{Ni}(\mathrm{OH})_{2}$ & $4.8 \times 10^{-20}$ & - \\
$\mathrm{Cu}(\mathrm{OH})_{2}$ & $1 \times 10^{-25}$ & $2.2 \times 10^{-20}$ \\
$\mathrm{Ag}(\mathrm{OH})$ & $3 \times 10^{-17}$ & - \\
$\mathrm{Zn}(\mathrm{OH})_{2}$ & $1.43 \times 10^{-20}$ & $1.8 \times 10^{14}$ \\
$\mathrm{~Pb}(\mathrm{OH})_{2}$ & & - \\
\hline
\end{tabular}

\section{Experimental Procedure}

The electrocoagulation experiments were performed in $1000 \mathrm{ml}$ beaker size reactor equipped with two carbon steel electrodes $(10 \mathrm{~cm} \times 14 \mathrm{~cm})$ that were $5 \mathrm{~mm}$ apart. As source of current and voltage a universal AC/DC adaptor was used. The pH was measured with a VWR scientific $8005 \mathrm{pH}$ meter (see Figure 3). The pregnant cyanide solutions were provided by the Bacis mining group.

The pregnant solution had a $\mathrm{pH} 12$ and was adjusted by adding solution of sulfuric acid. The conductivity was adjusted using $\mathrm{NaCl}$. EC was run at 10 Volts (DC) and the corresponding current was of 20 A.. EC was run on the samples, solutions and solids from the process were then separated by filtration through cellulose filter paper. The sludge from the EC was dried either in an oven or under vacuum at room temperature.

The parameters of the EC process for recovery of metal precious, experiments were conducted with by the same voltage and amperage, changing $\mathrm{pH}$ of the solution, and residence time in the EC cell, the solution initial concentration and the operational parameters are shown in Table 4 and Table 5.

To identify and characterize the species in the solid products, formed during the precipitation and EC process, were used Scanning Electron Microscope (SEM/EDX). Analysis of $\mathrm{Au}, \mathrm{Ag}, \mathrm{Cu}, \mathrm{Zn}$ and $\mathrm{Fe}$ were conducted to the Bacis solution, by AES.

\section{Precipitation}

The precipitation experiments were performed in $1000 \mathrm{ml}$ glass. In all the tests the initial solution was from the same batch (show Table 6). The following conditions were fixed: room temperature $25^{\circ} \mathrm{C}$; different $\mathrm{pH}$ using $\mathrm{H}_{2} \mathrm{SO}_{4}$ and different amounts of $\mathrm{Na}_{2} \mathrm{~S}$. The pregnant cyanide solutions were provided by the Bacis mining group.

\section{Results and Discussion}

Running the EC process for gold and silver removal on iron electrodes, the results are shown in Table 7 and Table 8. These results show the equilibrium concentration profile of gold and silver removal efficiency and final pHs values vs. time.

The obtained results show that EC is an excellent option to recovery Au and Ag from pregnant cyanide solution by using iron electrodes. Also, under these conditions, the results show that, when residence time increases from 10 to 20 minutes the silver and gold removal increase to $92 \%$ and $95 \%$ respectively, this variation occurs at $\mathrm{pH}$ values from 9 to 10, approximately; these values coincide with the production of magnetic iron, $\mathrm{Fe}_{3} \mathrm{O}_{4}$ (green rust). Also, it is apparent that the uptake percent's of gold/silver increased by increasing the $\mathrm{pH}$ value.

\subsection{Theoretical Analysis of the Electrocoagulation Process}

The average gold and silver content in pregnant solution was of 4.27 and 283 ppm, recovery was obtained of 92\% 


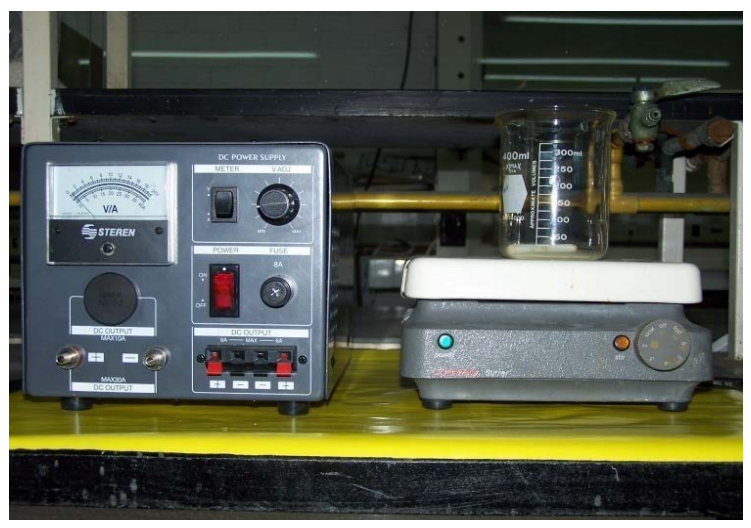

Figure 3. Laboratory equipment for electrocoagulation.

Table 4. Initial solution values of electrocoagulation.

\begin{tabular}{cccccc}
\hline Initial solution & $\mathrm{Au}(\mathrm{ppm})$ & $\mathrm{Ag}(\mathrm{ppm})$ & $\mathrm{Cu}(\mathrm{ppm})$ & $\mathrm{Zn}(\mathrm{ppm})$ & $\mathrm{Fe}(\mathrm{ppm})$ \\
Pregnant solution & 4.27 & 283 & 5899 & 8766 & 3997 \\
\hline
\end{tabular}

Table 5. Initial operating conditions of electrocoagulation.

\begin{tabular}{cccccc}
\hline Time (min) & Voltage (Volt) & Current (Amp) & Volume (ml) & NaCl (gr) & pH \\
\hline 10 & 10 & 20 & 1000 & 4 & $7,9,10,12$ \\
20 & 10 & 20 & 1000 & 4 & $7,9,10,12$ \\
\hline
\end{tabular}

Table 6. Initial solution values of precipitation process.

\begin{tabular}{ccccc}
\hline Initial solution & $\mathrm{Pb}(\mathrm{ppm})$ & $\mathrm{Cu}(\mathrm{ppm})$ & $\mathrm{Zn}(\mathrm{ppm})$ & $\mathrm{Fe}(\mathrm{ppm})$ \\
\hline Barren solution & 3.75 & 6569 & 8770 & 4277 \\
\hline
\end{tabular}

Table 7. Electrocoagulation process.

\begin{tabular}{|c|c|c|c|c|c|c|c|c|}
\hline Sample number & $\mathrm{Au}(\mathrm{ppm})$ & Ag (ppm) & $\mathrm{Pb}(\mathrm{ppm})$ & $\mathrm{Cu}(\mathrm{ppm})$ & Zn (ppm) & $\mathrm{Fe}(\mathrm{ppm})$ & Time (min) & $\mathrm{pH}$ \\
\hline 0 & 4.27 & 283 & 4.98 & 5899 & 8766 & 4997 & 0 & 12 \\
\hline 1 & 2.15 & 133 & 4.77 & 4434 & 6628 & 4306 & 10 & 7 \\
\hline 2 & 1.68 & 110 & 4.33 & 4058 & 5398 & 4189 & 20 & 7 \\
\hline 3 & 1.33 & 101 & 4.13 & 4312 & 5191 & 3781 & 10 & 8 \\
\hline 4 & 1.03 & 79 & 3.81 & 3742 & 4854 & 3108 & 20 & 8 \\
\hline 5 & 1.02 & 63.21 & 3.42 & 3276 & 4292 & 3170 & 10 & 9 \\
\hline 6 & 0.76 & 42.36 & 3.0 & 2841 & 3611 & 2827 & 20 & 9 \\
\hline 7 & 0.67 & 23.50 & 2.89 & 1361 & 2283 & 1718 & 10 & 10 \\
\hline 8 & 0.31 & 12.04 & 1.75 & 1012 & 1543 & 1099 & 20 & 10 \\
\hline
\end{tabular}

Table 8. \% Recovery of electrocoagulation process.

\begin{tabular}{|c|c|c|c|c|c|c|c|c|}
\hline Sample number & $\mathrm{Au}(\%)$ & Ag (\%) & $\mathrm{Pb}(\%)$ & $\mathrm{Cu}(\%)$ & $\mathrm{Zn}(\%)$ & $\mathrm{Fe}(\%)$ & Time (min) & $\mathrm{pH}$ \\
\hline 1 & 49.64 & 53 & 4.21 & 24.83 & 24.38 & 13.82 & 10 & 7 \\
\hline 2 & 60.65 & 61.13 & 13.05 & 31.2 & 38.42 & 16.16 & 20 & 7 \\
\hline 3 & 68.85 & 64.31 & 17.06 & 26.9 & 40.78 & 24.33 & 10 & 8 \\
\hline 4 & 75.87 & 72.08 & 23.49 & 36.56 & 44.62 & 37.8 & 20 & 8 \\
\hline 5 & 76.11 & 77.66 & 31.32 & 44.46 & 51.03 & 36.56 & 10 & 9 \\
\hline 6 & 82.2 & 85.03 & 39.75 & 51.83 & 58.8 & 43.42 & 20 & 9 \\
\hline 7 & 84.3 & 91.69 & 41.96 & 76.92 & 73.95 & 65.61 & 10 & 10 \\
\hline 8 & 92.74 & 95.74 & 64.85 & 82.28 & 82.39 & 78 & 20 & 10 \\
\hline
\end{tabular}


of gold and $95 \%$ of silver, with this optimum operating parameters, $\mathrm{pH} 10$, residence time 20 minutes and conductivity by addition of sodium chloride $4 \mathrm{gr} / \mathrm{L}$. Based on the results presented in Table 6 and Table 7, the rate of electrocoagulation process for adsorption of gold and silver in magnetic particles the reaction is expected to be a function of the surface area and the concentration of the reacting noble metal ion (gold or silver in the present case), therefore were used the first-order equation, see Figure 4.

It was demonstrated that the recovery of gold and silver follows the first order rate equation according to the obtained values of $\mathrm{R}^{2}$ and correlation factor, see Table 9, obtained from the kinetic constant slope.

The equilibrium concentration profiles (on logarithmic scale), the results were found to conform to the firstorder rate process for over $90 \%$ removal as shown in figure $(\mathrm{Au} / \mathrm{Fe}(\mathrm{CN})$-system) and $(\mathrm{Ag} / \mathrm{Fe}(\mathrm{CN})$-system). From these data it is evident that the cementation of both gold and silver by zinc conforms to well-behaved fist order kinetics. Also, from these figure, the micrograph of reacted iron particles can be seen.

This micrograph reveals the nature of the silver and gold deposits. The effect of the gold and silver deposits on the rate of electrocoagulation reaction product showed that the gold and silver formed uniforms, apparently porous layer around the iron particle.

\subsection{Precipitation}

The precipitation process for gold, silver, lead, cooper, zinc and iron removal, gave the results shown in Table 10 and Table 11 (\% Recovery) shows the equilibrium concentration profile of gold and silver removal efficiency and final pHs values vs. time.

The results showed the nature, surface, and settling characteristics of the gold, silver, zinc, lead, iron, cooper sulfide precipitates were found to be strongly influenced by sulfide availability and speciation and operating $\mathrm{pH}$.

\subsection{Scanning Electron Microscopy (SEM/EDAX)}

Figure 5 and Figure 6 shows SEM and EDX of silver adsorbed on iron species. SEM microphotography shows that the surfaces of these iron oxide/oxyhydroxide particles were coated with a layer of silver. The chemical composition of solid product as determined by EDX, with this analytical technique used for the elemental analysis or chemical characterization, identify the iron, silver and other elements like calcium and copper, the maximum number of counts from spectrum corresponds to iron and less counts at the other elements include the silver, then we can concluded what the silver is adsorbed on the particle of iron like shows SEM image. Show Figure 5. Table 12 shows chemical composition the solid product of electrocoagulation process determined by EDX.

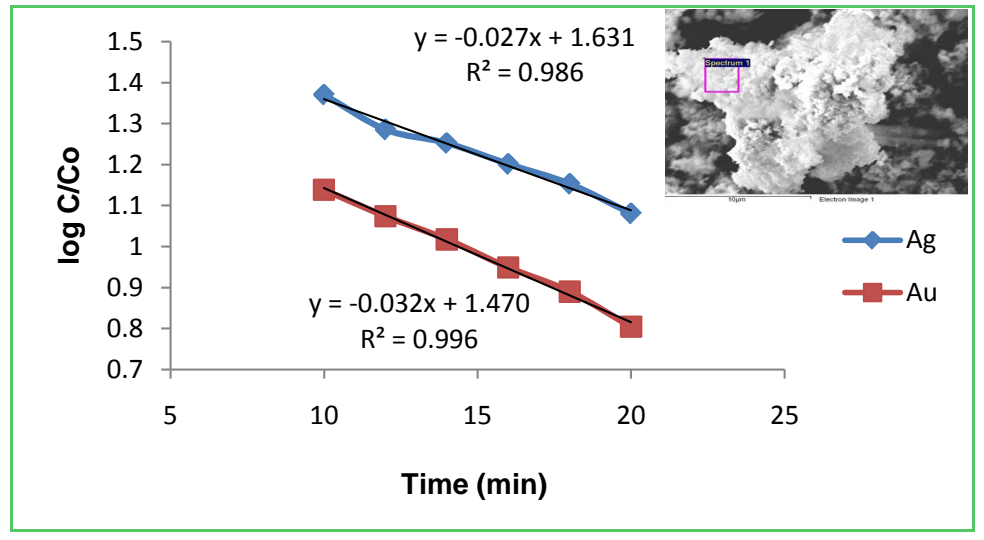

Figure 4. Graphical rate equation of the first order.

Table 9. Correlation factor and kinetic constant values.

\begin{tabular}{ccc}
\hline & $\mathbf{R}^{2}$ & $\mathbf{K}$ \\
\hline Au & 0.9964 & 0.0328 \\
Ag & 0.9864 & 0.0272 \\
\hline
\end{tabular}


Figure 6 shows SEM and EDX of lead, cooper, zinc and iron. SEM microphotography shows the surface of particles. The chemical composition of solid product as determined by EDX, with this analytical technique used for the elemental analysis or chemical characterization, identify the lead, cooper, zinc and iron and other elements like calcium, chlorine, manganese and silicon. Table 13 shows chemical composition the solid product of precipitation process determined by EDX.

Table 10. Results of precipitation process.

\begin{tabular}{ccccccccc}
\hline Sample number & $\mathrm{Na}_{2} \mathrm{~S}(\mathrm{gr} / \mathrm{L})$ & $\mathrm{H}_{2} \mathrm{SO}_{4}(\mathrm{~N})$ & $\mathrm{Pb}(\mathrm{ppm})$ & $\mathrm{Cu}(\mathrm{ppm})$ & $\mathrm{Zn}(\mathrm{ppm})$ & $\mathrm{Fe}(\mathrm{ppm})$ & Time $(\mathrm{min})$ & $\mathrm{pH}$ \\
\hline 0 & 0 & 0 & 3.75 & 6569 & 8770 & 4277 & 0 & 12 \\
1 & 5 & 0.006 & 3.32 & 1843 & 1602 & 1452 & 15 & 10 \\
2 & 5 & 0.008 & 1.88 & 2104 & 1770 & 1610 & 15 & 9 \\
3 & 5 & 0.01 & 1.37 & 1113 & 1569 & 1050 & 15 & 8 \\
4 & 5 & 0.012 & 1.17 & 1093 & 1419 & 699 & 15 & 7 \\
5 & 10 & 0.014 & 1.01 & 680 & 352 & 403 & 15 & 6 \\
6 & 10 & 0.016 & 0.91 & 405 & 167 & 267 & 15 & 5 \\
7 & 10 & 0.018 & 0.80 & 168 & 49 & 50 & 15 & 4 \\
8 & 10 & 0.02 & 0.5 & 59 & 40 & 10 & 15 & 3 \\
\hline
\end{tabular}

Table 11. \% Recovery of precipitation process.

\begin{tabular}{ccccccccc}
\hline Sample number & $\mathrm{Na}_{2} \mathrm{~S}(\mathrm{gr} / \mathrm{L})$ & $\mathrm{H}_{2} \mathrm{SO}_{4}(\mathrm{~N})$ & $\mathrm{Pb}(\mathrm{ppm})$ & $\mathrm{Cu}(\mathrm{ppm})$ & $\mathrm{Zn}(\mathrm{ppm})$ & $\mathrm{Fe}(\mathrm{ppm})$ & $\mathrm{Time}(\mathrm{min})$ & $\mathrm{pH}$ \\
\hline 1 & 5 & 0.006 & 11.46 & 67.97 & 79.81 & 62.35 & 15 & 10 \\
2 & 5 & 0.008 & 40.86 & 71.94 & 81.73 & 66.05 & 15 & 9 \\
3 & 5 & 0.01 & 63.46 & 83.05 & 82.10 & 75.45 & 15 & 8 \\
4 & 5 & 0.012 & 68.80 & 83.36 & 83.81 & 83.65 & 15 & 7 \\
5 & 10 & 0.014 & 73.06 & 89.64 & 95.98 & 90.57 & 15 & 6 \\
6 & 10 & 0.016 & 86.66 & 93.83 & 98.09 & 93.75 & 15 & 5 \\
7 & 10 & 0.018 & 97.33 & 97.44 & 99.44 & 98.83 & 15 & 4 \\
8 & 10 & 0.02 & 99.20 & 99.10 & 99.54 & 99.76 & 15 & 3
\end{tabular}

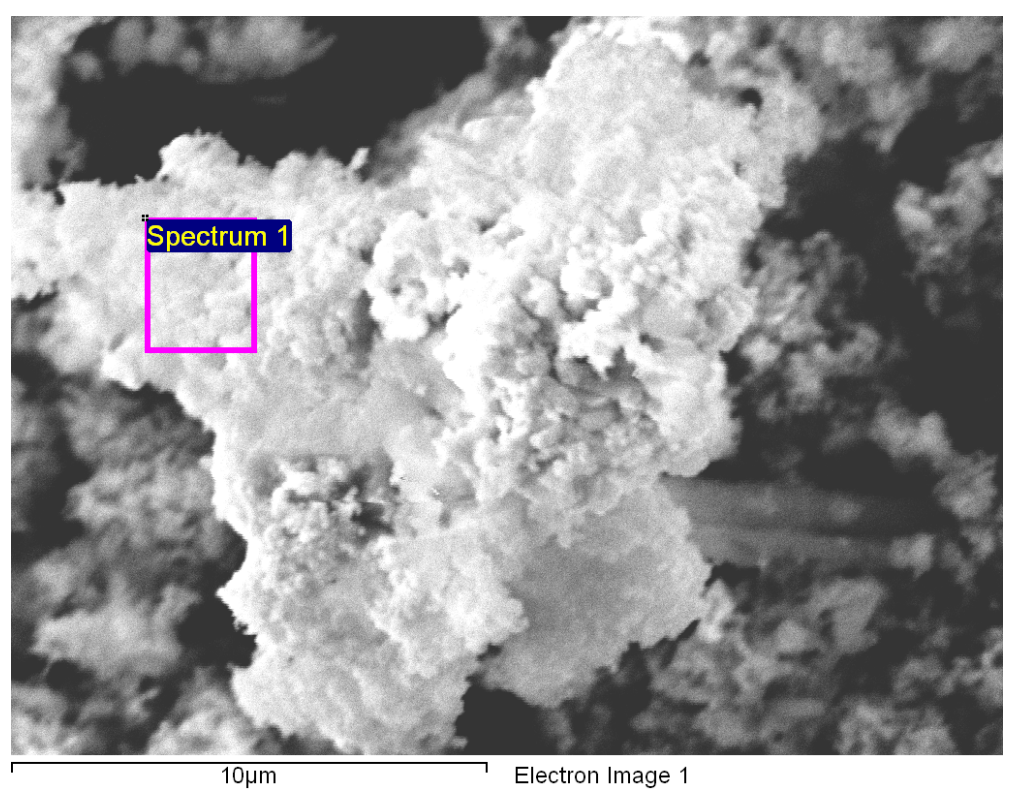




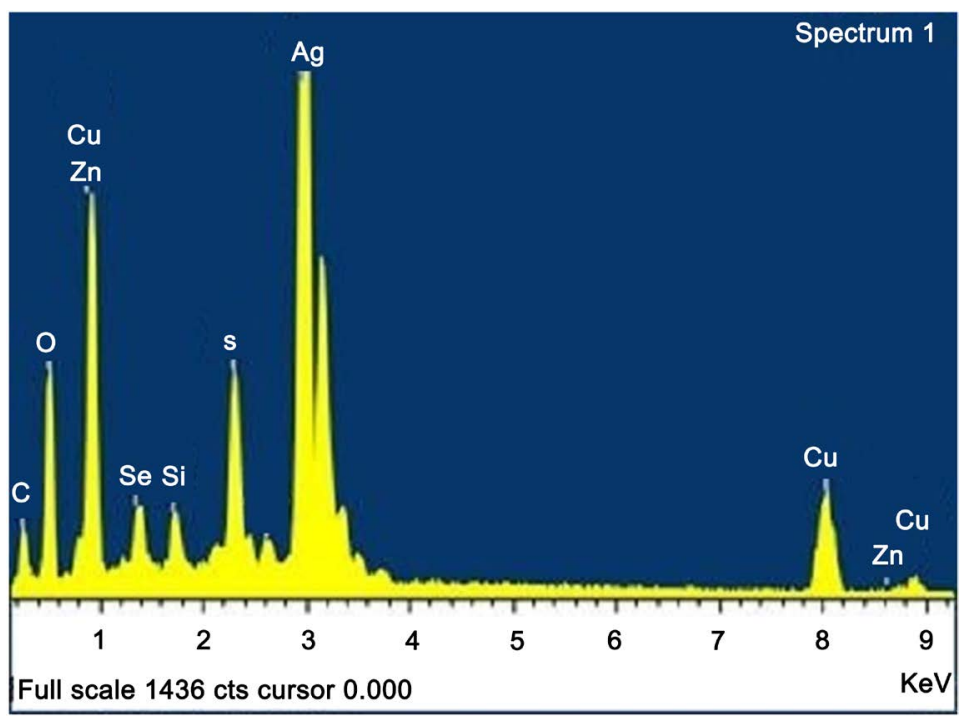

Figure 5. SEM and EDAX images for by products generated from EC of pregnant solution.
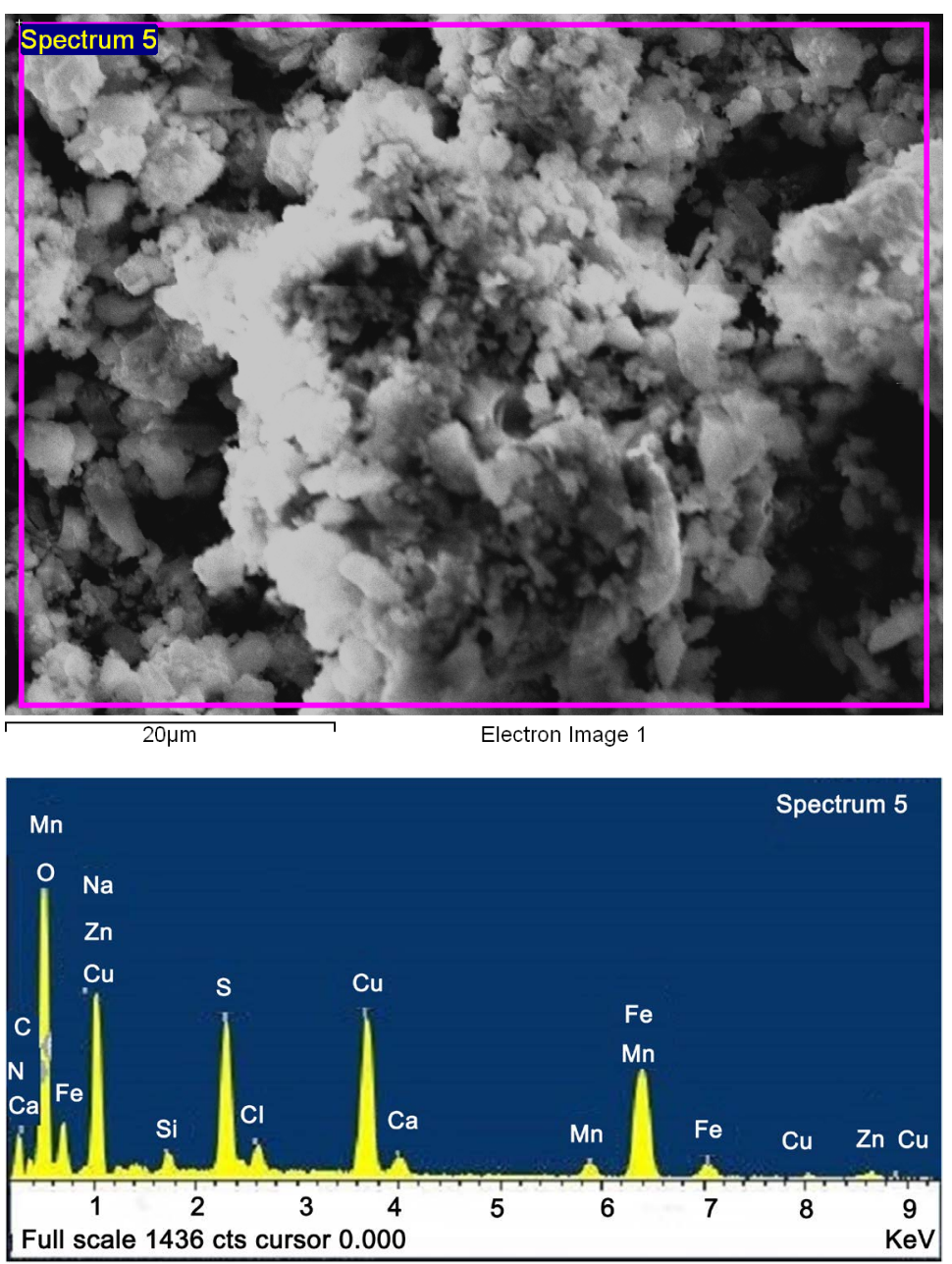

Figure 6. SEM and EDAX images for by products generated from precipitation process. 
Table 12. EDAX, elemental analysis or chemical characterization.

\begin{tabular}{ccc}
\hline Element & Weight \% & Atomic \% \\
\hline CK & 5.25 & 14.63 \\
OK & 27.27 & 57.06 \\
SiK & 1.15 & 1.38 \\
SK & 4.02 & 4.19 \\
CuK & 14.40 & 7.59 \\
ZnK & 0.31 & 0.16 \\
SeL & 2.94 & 1.25 \\
AgL & 45.28 & 14.06 \\
\hline
\end{tabular}

Table 13. EDAX, elemental analysis or chemical characterization.

\begin{tabular}{ccc}
\hline Element & Weight \% & Atomic \% \\
\hline CK & 11.15 & 18.43 \\
NK & 7.01 & 9.94 \\
OK & 39.47 & 48.97 \\
NaK & 9.75 & 8.42 \\
SiK & 0.61 & 0.43 \\
SK & 5.21 & 3.23 \\
ClK & 0.99 & 0.56 \\
CaL & 7.00 & 3.47 \\
MnL & 1.55 & 0.56 \\
FeK & 14.45 & 5.14 \\
CuK & 0.71 & 0.22 \\
ZnK & 2.09 & 0.64 \\
\hline
\end{tabular}

\section{Conclusions}

The obtained results show that EC process is an excellent option for the recovery of Au and Ag from pregnant cyanide solution by using iron electrodes. The experimental reaction velocity constants correspond to the expected magnitude of the limiting mass-transfer coefficients and support the hypothesis that the electrocoagulation reactions under these conditions are mass-transfer limited reactions with recoveries of gold and silver of $92 \%$ and $95 \%$ respectively.

The results of precipitation process show that the elimination of lead, zinc, cooper and iron ions from barren solution was successful, with optimum operating parameters in the range of pH 4 to 3 and residence time of 15 minutes, and the recoveries were $99 \%$ of these ions.

Scanning Electronic Microscopy demonstrates that the formed species are of magnetic type, like lepidocrocite, magnetite and amorphous iron oxyhydroxide which adsorbed the silver and gold particles on the surface due to the electrostatic attraction between both metals.

\section{Acknowledgements}

The authors gratefully acknowledge to the National Council of Science and Technology (CONACYT) and Department of Chemical Engineering and Metallurgical of University of Sonora.

\section{References}

[1] Habashi, F. (1967) Kinetics and Mechanism of Gold and Silver Dissolution in Cyanide Solution. Montana Bureau of Mines Geological Bulletin, 59, 1-42.

[2] Dai, X. and Jeffrey, M.I. (2006) The Effect of Sulphide Minerals on the Leaching of Gold in Aerated Cyanide Solu- 
tions. Hydrometallurgy, 82, 118-125. http://dx.doi.org/10.1016/j.hydromet.2006.03.005

[3] Fink, C.G. and Putnam, G.L. (1950) The Action of Sulphide Ion and for Metal Salts on the Dissolution of Gold in Cyanide Solutions. Transactions AIME, 187, 952-955.

[4] Hedley, N. and Tabachnick, H. (1968) Chemistry of Cyanidation. Mineral Dressing Notes No. 23, American Cyanamid Company, New Jersey.

[5] Brooy, S.R. and Linge, H.G. (1996) Review of Gold Extraction from Ores. Mineral Engineering, 7, 1213-1241. http://dx.doi.org/10.1016/0892-6875(94)90114-7

[6] Habashi, F. (2005) A Short History of Hydrometallurgy. Hydrometallurgy, 79, 15-22. http://dx.doi.org/10.1016/0892-6875(94)90114-7

[7] Parga, J.R., Gonzalez, G., Moreno, H. and Valenzuela, J.L. (2012) Thermodynamic Studies or the Strontium Adsoption on Iron Species Generated by Electrocoagulation. Desalination and Water Treatment, 37, 244-252. http://dx.doi.org/10.1016/0892-6875(94)90114-7

[8] Martinez, G.V.F., Torres, J.R.P., Garcia, J.L.V., Munive, G.C.T. and Zamarripa, G.G. (2012) Kinetic Aspects of Gold and Silver Recovery in Cementation with Zinc Power and Electrocoagulation Iron Process. Advances in Chemical Engineering and Science, 2, 342-349. http://dx.doi.org/10.4236/aces.2012.23040

[9] Rehman, I. and Bonfield, W. (1997) Characterization of Hydroxyapatite and Carbonated Apatite by Photo Acoustic FTIR Spectroscopy. Journal of Materials Science Materials in Medicine, 8, 1-4. http://dx.doi.org/10.1023/A:1018570213546

[10] Rayanaud, S., Champion, E., Bernache-Assollant, D. and Thomas, P. (2002) Characterization and Thermal Stability of Powders. Biomaterials, 23, 1065-1072.

[11] Bagotsky, V.S. (2006) Fundamentals of Electrochemistry. 2nd Edition, John Wiley \& Sons, Inc., New Jersey, 44.

[12] Lapidus, G. (1995) Unsteady-State Model for Gold Cyanidation on a Rotating Disk. Hydrometallurgy, 39, $251-263$. http://dx.doi.org/10.1016/0304-386X(95)00033-D

[13] Jin, S., May, O., Ghali, E. and Deschenes, G. (1998) Investigation on the Mechanisms of the Catalytical Effect of Lead Salts on Gold Dissolution in Cyanide Solution. In: Yang, X.W., Chen, Q.Y. and He, A.P., Eds., Proceedings of Third International Conference on Hydrometallurgy, ICHM’98, International Academic Publishers, Beijing, 666-679.

[14] Mollah, M., Morkovsky, P., Gomez, J., Kesmez, M., Parga, J.R. and Cocke, D. (2004) Fundamentals, Present and Future Perspectives of Electrocoagulation. Journal of Hazardous Materials, 114, 199-210. http://dx.doi.org/10.1016/j.jhazmat.2004.08.009

[15] Emamjomeh, M.M. and Sivakumar, M. (2009) Review of Pollutants Removed by Electrocoagulation and Electrocoagulation/Flotation Processes. Journal of Environmental Management, 90, 1663-1679. http://dx.doi.org/10.1016/j.jenvman.2008.12.011

[16] Zhao, X., Zhang, B.F., Liu, H.J. and Qu, J.H. (2010) Removal of Arsenite by Simultaneous Electro-Oxidation and Electro-Coagulation Process. Journal of Hazardous Materials, 184, 472-476.

[17] Senanayake, G. (2006) The Cyanidation of Silver Metal: Review of Kinetics and Reaction Mechanism. Hydrometallurgy, 81, 75-85. http://dx.doi.org/10.1016/j.hydromet.2005.12.001

[18] Ku, Y. and Jung, I.L. (2001) Photocatalytic Reduction of $\mathrm{Cr}(\mathrm{VI})$ in Aqueous Solutions by UV Irradiation with the Presence of Titanium Dioxide. Water Research, 35, 135-142. http://dx.doi.org/10.1016/S0043-1354(00)00098-1

[19] Lewis, A.E. (2010) Review of Metal Sulphide Precipitation. Hydrometallurgy, 104, 222-234.

[20] Lewis, A. and van Hille, R. (2006) An Exploration into Sulphide Precipitation Method and Its Effect on Metal Sulphide Removal. Hydrometallurgy, 81, 197-204. http://dx.doi.org/10.1016/j.hydromet.2005.12.009 
Scientific Research Publishing (SCIRP) is one of the largest Open Access journal publishers. It is currently publishing more than 200 open access, online, peer-reviewed journals covering a wide range of academic disciplines. SCIRP serves the worldwide academic communities and contributes to the progress and application of science with its publication.

Other selected journals from SCIRP are listed as below. Submit your manuscript to us via either submit@scirp.org or Online Submission Portal.
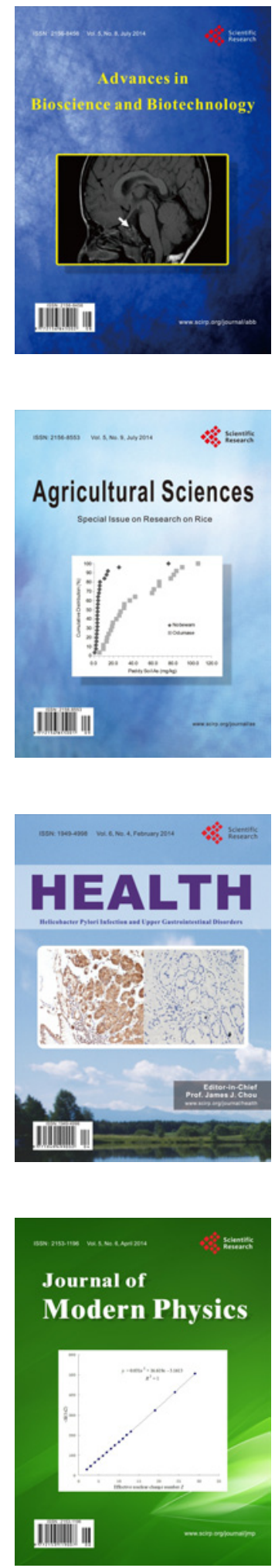
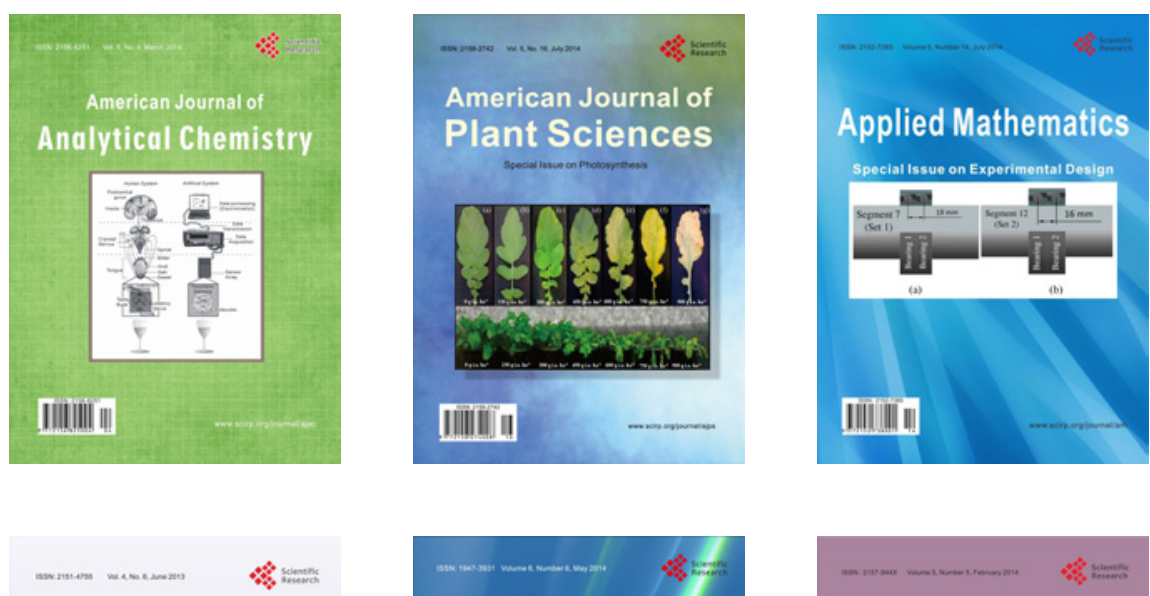

Creative Education
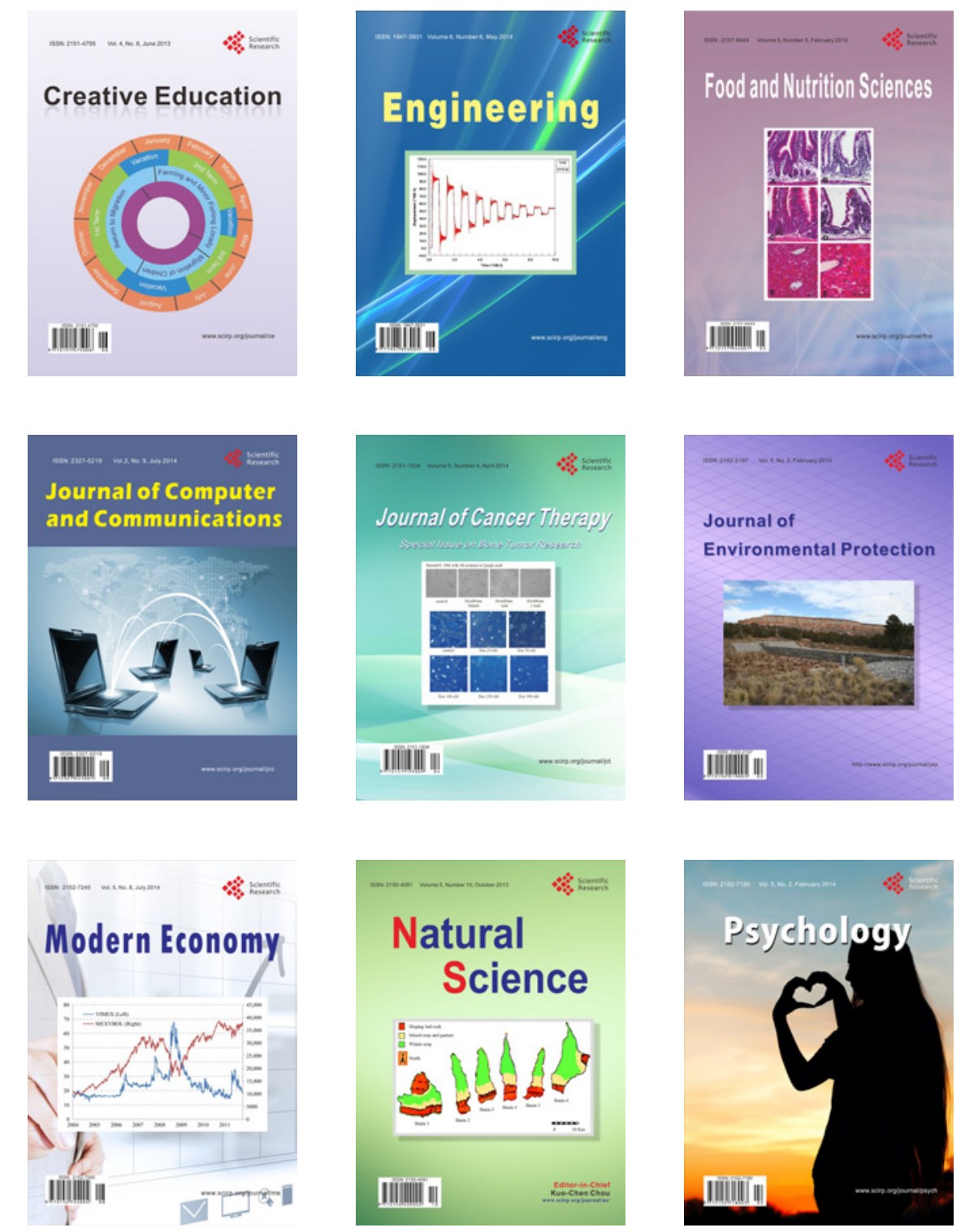